\title{
Prevalence of disordered eating in athletes categorized by emphasis on leanness and activity type - a systematic review
}

\author{
Ryley P. Mancine ${ }^{1 *}$ D, Donald W. Gusfa ${ }^{1}$, Ali Moshrefi ${ }^{2}$ and Samantha F. Kennedy ${ }^{3}$
}

\begin{abstract}
Background: Disordered Eating (DE) shows a strong association with athletics and can lead to several negative mental and physical health effects. Traditionally, sports have been grouped based upon whether or not the sport emphasizes leanness as a competing factor. Due to sociocultural factors, risk for DE may also be associated with the sport type. The aim of this review is to critically analyze the available research and data in this field to consider the relationship between DE and sport type to see which factors influence prevalence among athletes

Method: A systematic review was completed using keywords specific to DE and sport types. Articles were either excluded due to lack of specification of athlete type or failure to use a standardized screening tool or interview for data collection.

Results: 6 out of 7 studies found a significant increase in DE rates among lean sport types. When classifying by sport type reports were less consistent, but show non-lean sports also have increased rates of DE.

Conclusion: There are variations in prevalence of DE behaviors depending on athlete type. It is important to identify the risk for DE early in athletes so emphasis can be placed on treatment options to nullify progression to an eating disorder, lower negative impacts on an athlete's performance, and prevent other negative health effects. Using sport groups is important to clinical practice as well as research, as certain sports may have a higher risk for development of DE.
\end{abstract}

Keywords: Eating disorders, Sport group, Sports mental health, Leanness, Activity group, Disordered eating

\section{Plain english summary}

For athletes, disordered eating can progress to an eating disorder, which has a multitude of physical and mental health consequences. Certain types of athletes may be at an increased risk for disordered eating behaviors. This manuscript attempts to categorize sport types to determine which groups of athletes may have the highest incidence of disordered eating. It also attempts to determine if there are major differences in the presentation of

\footnotetext{
* Correspondence: manciner@msu.edu

${ }^{1}$ Medical Student, Michigan State University College of Osteopathic Medicine, Michigan State University, East Lansing, MI 48825, USA

Full list of author information is available at the end of the article
}

disordered eating behaviors between different sport types. It is important to identify the risk for disordered eating in athletes of all types so that disordered eating behaviors may be halted before they progress to an eating disorder, which is much more difficult to treat. This systematic review of the literature aims to discover differences between the different types of sport as they relate to disordered eating behavior rates, risks, and pathologies.

\section{Introduction}

Over the past fifteen years, there has been an increase in research on eating pathology in sports [1]. Eating pathology is often described as a continuum ranging from 
disordered eating (DE) to a clinical eating disorder (ED). DE encompasses symptoms of dysfunctional eating patterns such as fasting, dieting, vomiting, over-eating, binge eating and use of laxatives and/or diet pills [2]. In athletes, $\mathrm{DE}$ frequently occurs due to the desire to achieve a sportspecific body-ideal and alleviate sport-specific body dissatisfaction [3]. DE can lead to EDs if left unaddressed and can cause increased incidence of mood, anxiety, and substance abuse disorders $[4,5]$. ED are clinical diagnoses that meet DSM-5 criteria, including Anorexia Nervosa (AN), Bulimia Nervosa (BN), and Other Specified Feeding and Eating Disorder (OSFED) [6, 7].

Estimates of the prevalence of DE among athletes varies widely in research due to the different populations of athletes studied (different sports, ages, levels of competitiveness, gender, etc.). In a study of DE amongst elite adolescent athletes by Martinsen et al., 606 Norwegian first year elite sport high school athletes reported higher prevalence of DE compared to the control group [8]. It was found that in the athlete group there was a significantly higher prevalence of DE in females who participated in lean sports compared to males in the same group [8]. Athletes competing in sports such as gymnastics, figure skating, diving, and dancing, where leanness is emphasized, have been found to be at higher risk of $\mathrm{DE}$, which frequently leads to a decrease in sport performance [9].

Perfectionism plays a role in the psychological impact of $\mathrm{DE}$ in an athlete, acting both as a symptom and a risk factor for DE [10]. Perfectionism often influences an athlete to have unrealistic expectations, which can result in dissatisfaction with body image and sport performance [5]. Research has found a correlation between DE and perfectionism, with an emphasis on precision and personal expectation for an athlete to achieve a sportspecific body to improve performance [10].

The female athlete triad encompasses three disorders in female athletes: DE, amenorrhea and osteoporosis [11]. This is demonstrated in the desire to lose weight to achieve a sport-specific body ideal, commonly resulting in an energy deficit, which may lead to amenorrhea and osteoporosis. Additionally, this energy deficit will ultimately result in poor performance [10]. A study by Cobb et al. examined 91 competitive female distance runners ages 18-26 years and found that female runners with poor nutrition and irregular eating patterns had an energy imbalance, which often led to amenorrhea [12]. The female athlete triad refers to female athletes of all kinds of sports, regardless of sport type category. While the term 'female athlete triad' has been established for many years, more recently the term 'Relative Energy Deficiency in Sport' (RED-S) has been used to describe these same three traits coupled with a multitude of other systemic consequences that are associated with low energy availability [13]. RED-S syndrome demonstrates the multitude of physiological consequences associated with $\mathrm{DE}$, such as hematological, cardiovascular, and gastrointestinal disruptions.

Athletes can be divided into lean and non-lean categories. Lean sports emphasize achieving and maintaining a lower body weight due to the belief that lower body weight improves performance [8]. A few examples of lean sports include dancing, judo, long-distance running, swimming, and diving $[8,14]$. Alternatively, nonlean sports do not require a low body weight in order for an athlete to be competitive [15]. Some non-lean sports include golf, basketball, table tennis, and horse riding [8]. Lean sports may increase risk for DE because athletes may engage in pathogenic weight-control behavior to achieve a lower body weight [16]. A study by Kong et al. found athletes participating in lean sports scored higher on the Eating Attitudes Test (EAT-26) compared to athletes competing in non-lean sports. Additionally, lean sport athletes reported significantly more eating pathology compared to non-competitive athletes with $84 \%$ of the female athletes who screened positive participating in lean sports $[15,17]$. Examples of sports that fit into each category, along with categories of sports that make up lean and non-lean sports, are referenced in Fig. 1.

Sports can be further divided into six categories: aesthetic, weight-dependent, endurance, ball game, power, and technical sports [18]. Of these categories, aesthetic, weight-dependent and endurance sports are typically considered lean sports, whereas ball game, power and technical sports are considered non-lean sports.

In aesthetic sports, the performance of an individual or team is assessed by a judge or judges of the competition [19]. In aesthetic sports, the winner is determined by judging an individual or team performance using a complex set of rules [19]. Thus, appearance is a major factor in the judging. Examples of aesthetic sports include gymnastics, diving, figure skating, dancing, ballet [16]. All of these sports are considered lean sports due to the pervasive belief that a lower body weight results in more favorable judging [20].

Weight-dependent sports divide competitors into different categories based on the weight of the competitor. Examples of weight-dependent sports include wrestling, karate, and judo [18]. Studies have shown athletes competing in weight-dependent sports are at an increased risk for eating pathology, such as DE, compared to nonathletes [21]. This is likely due to athletes attempting to achieve lower body weight while maintaining muscle mass to gain a competitive advantage by competing in a lower weight class. Athletes competing in weightdependent sports may utilize pathogenic weight control behaviors to achieve rapid weight loss prior to a 

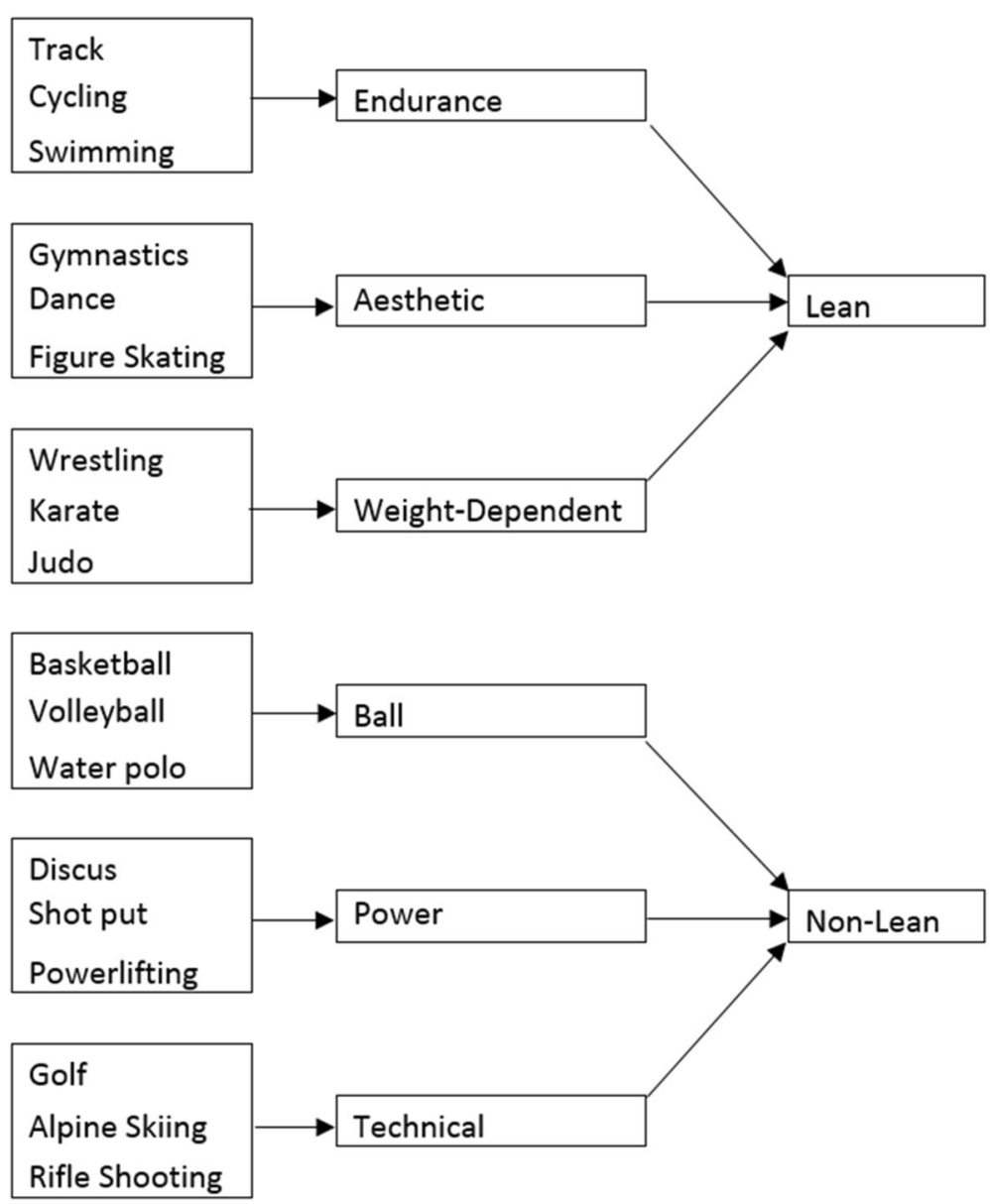

Fig. 1 Examples of various sports and the categories they fit in. The groupings of sports that define lean and non-lean sports are also provided

competition in order to achieve higher levels of success [8]. Due to this emphasis on achieving a low body weight, weight-dependent sports can be categorized as lean sports.

Endurance sports include cycling, rowing, running, swimming, cross-country skiing and speed skating [18, 22]. In these sports, a lower body weight is typically associated with a higher level of competition [23]. As a result, endurance athletes may utilize abnormal eating behaviors to achieve a body weight that is too low, resulting in an energy imbalance. This imbalance of energy is a frequent consequence of DE in endurance athletes due to the high metabolic requirements of highvolume aerobic training [22, 24]. Thus, endurance sports can also be categorized as lean sports.

Ball-game sports involve a ball where the objective is to move the ball between members of the same team with a specific goal to score more points than the other team [18]. Ball sports include football, soccer, and volleyball, as well as bat/stick sports (hockey, baseball, cricket) $[15,18]$. Ball-game sports are considered nonlean sports as performance is determined by the athlete's ability to maneuver the ball as desired and thus is not dependent on a specific weight.

Power sports emphasize strength and include powerlifting, shot put, and sprinting $[18,25]$. The goal in these sports is to maximize strength and power to improve performance [25]. Appropriate nutrition plays a fundamental role in the athlete's ability to increase strength and muscle mass for competitive success [25]. Thus, power sports are considered non-lean sports due to this desire to achieve strength.

Technical sports place an emphasis on a certain skill with a piece of specialized equipment [18]. An example of a technical sport is rifle shooting [18]. There has been very little research on eating behaviors in technical sports. However, as this category of sport emphasizes a specific skill and not a specific body type, it can be categorized as a non-lean sport.

Some sports may have higher prevalence rates of DE than other sports, and it is important to consider different activities and focus groups when assessing for prevalence of DE. Athletes who participate in endurance sports have a higher emphasis on aerobic training 
compared to others [18]. When emphasis is placed on different aspects of training and competition, one can expect an outcome that entices an athlete to continue pursuing the method that allowed them to gain a competitive advantage. In doing so, this may result in the athlete normalizing irregular diet patterns/quantity with respect to their training, resulting in DE.

This systematic literature review is, as far as the authors are aware, first of its kind to date to examine current data in the field of DE in leanness athletes and other activity types to assess for prevalence. It is critical to understand the potential risk factors that are present for athletes, making them susceptible to further health complications. By evaluating the athlete for DE, it facilitates early detection of irregular eating patterns that could lead to ED. This systematic review aims to address the variable prevalence and presentation of $\mathrm{DE}$ behaviors in the various types of athletes.

\section{Methods}

\section{Search strategy and data reporting}

The PubMed database was the primary source of collected articles. Articles accessed were published between January 2000 and July 2019. All articles were obtained after the year 2000 to provide an insight into the most recent developments of research within the field. Articles were screened for the terms "Athletes," "Disordered Eating," "aesthetic," "power," "endurance," "technical," "ball, " "weight dependent," and "leanness." Articles that did not directly answer the research question "Which athlete groupings would be more susceptible to DE?" or report on DE or athletes specifically were not included. This review article follows all acceptable research practices and ethical considerations as outlined by Navalta et al. [26]. Suitable articles in this study were individually reported on, with correlation and possible weaknesses being stated in the interpretation portion of the tables. These interpretations were then reviewed by our research team to validate the original analysis. All participants defined as athletes (novice or elite) were included in this review to allow for significant amounts of data to be collected. These athletes needed to be defined as having DE using at least one standardized screening tool or interview. There were no restrictions on control groups.

\section{Selection of studies}

A detailed flowchart of the search strategy can be seen in Fig. 2. 155 articles were initially identified in a preliminary literature search, but initial text analysis for keywords resulted in 119 articles being removed from analysis. Articles were included based on the following analysis of abstracts: [1] peer-reviewed published work

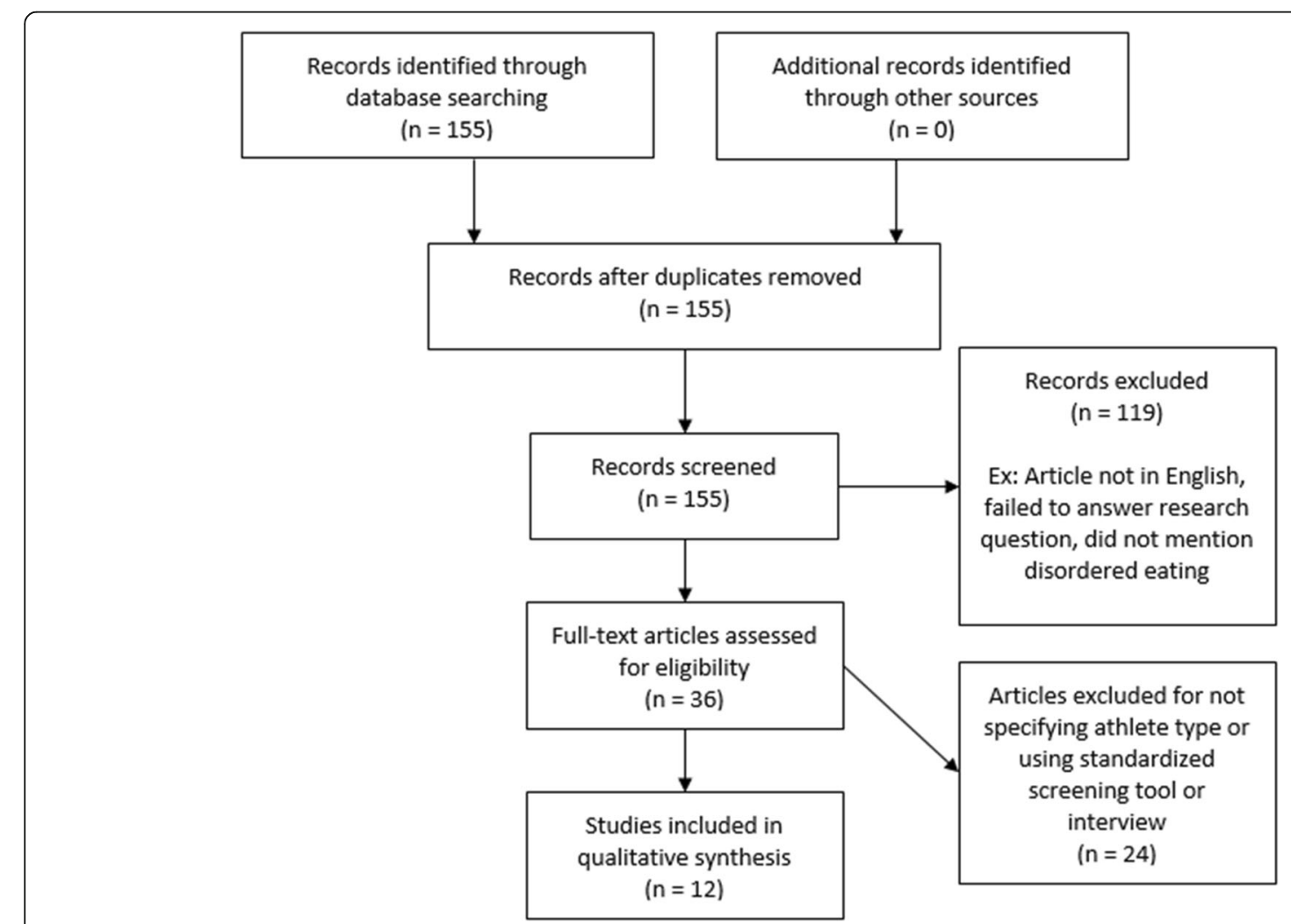

Fig. 2 PRISMA-guided literature search methods 
in the English language, [2] specific mention of DE or an ED in athletes, [3] outcome measures which included prevalence rates of DE. Each included article was reviewed independently by two authors to ensure appropriate criteria were met. Evaluation of the subsequent texts based on relevance to the hypothesis resulted in the removal of 9 articles, leaving 27 in the review. Further articles were excluded upon full-text analysis due to their lack of specification of athlete type or that they did not use a standardized screening tool or interview such as the EAT-26 or EDE-17. Therefore, there were 12 articles that specifically fit the research question. These athlete types were reported in two tables based on whether they were categorized as "lean" or a specific sport type. If an individual sport was reported it was categorized into the prior mentioned categories.

\section{Results}

\section{Comparison of lean vs non-lean sport groupings}

Research on lean sports found athletes participating in lean sports had significantly higher rates of DE than non-lean sports in 6 out of 7 studies (Table 1). In one of these studies, different sports did not have a statistically significant difference in rates of DE [29]. However, when the sports were grouped into "Lean" and "Non-Lean" categories, the difference in the rates of DE between the two categories was statistically significant.

\section{Comparison of activity type sport groupings}

Five studies divided sports into activity subgroups, which were then analyzed for risk for DE (Table 2). Two studies found that aesthetic sports had a higher prevalence of DE $[6,9]$. Aesthetic sports place an emphasis on leanness and thus are considered lean sports [20]. This could explain the lack of a statistically significant difference in prevalence rates of $\mathrm{DE}$ in the study by Vander et al. as only 6 of the 72 athletes studied competed in aesthetic sports [29]. By contrast, in the study by Kong et al., $60.9 \%$ of the lean athletes competed in aesthetic sports [15]. This study found a higher prevalence of DE in lean sports.

A study by Chatterton et al. analyzing DE in male athletes found weight class sports had a significantly higher prevalence of DE compared to endurance and ball game sports [31]. A study by Rosendahl et al. analyzed multiple sport types and found Power and Antigravitation sports had a significantly higher prevalence of $\mathrm{DE}$ when adjusted for gender. Additionally, they found Endurance, Aesthetic, Weight-Dependent, Technical and Ball Game sports had no statistically significant difference [30]. Kampouri et al. analyzed three Ball Game sports and found different prevalence rates of $\mathrm{DE}$ between the sports. They found water polo had a higher prevalence of DE than volleyball or basketball [32]. Currently, there is not enough information on which sport or sport type has relation to $\mathrm{DE}$ indicating further research is required for clarification on which sports have the highest risk for DE.

Lean sports have a higher prevalence of DE when studied either directly (Table 1 ) or indirectly (Table 2 ). However, there were multiple inconsistencies regarding the higher prevalence of DE in lean sports when specific sport types were studied (Table 2). For example, some non-lean power [30] sports were found to have a higher prevalence of DE while some endurance [30,31] lean sports did not show statistically significant differences. This implies that sensitivity may be higher when dividing sports as lean versus non-lean [32], but specificity may be higher when dividing sports by type (Aesthetic, Weight-dependent, Endurance, Ball Game. Power, Technical) [30].

\section{Discussion}

$\mathrm{DE}$ is common amongst athletes, but there is still much to learn about the prevalence within certain subgroups. Though there is clear evidence that an emphasis on leanness plays a role $[3,8,15,27,29,30]$, divisions into further subgroups show less concise evidence. When subdividing sports into activity type, aesthetic sports seem to be consistently correlated with an increase in DE rates [6,9]. Further, the only article who found lean sports did not show higher rates of DE did not have many aesthetic sport athletes within their lean group [29]. This indicates that, though useful, the lean grouping does not provide a complete picture when addressing DE risk. The rest of the significant positive findings were shown in weight-dependent [31], power [32], antigravitation [32], and the specific ball sport water polo [27]. These provide insight into the risk of more specific groupings and therefore the risk factors of $\mathrm{DE}$ in athletes, but due to lack of evidence nothing more definitive can be said about the sport type groupings at this time. That said, these findings could serve as a guide for further research aimed at defining these rates within certain sports.

Athletes participating in lean sports compete in different environments and train differently than athletes participating in non-lean sports. Thus, risk factors for DE in athletes are unique to the demands of the sport environment (e.g. high-pressure situations with constant observation and performance-based evaluations). With knowledge of potential high-risk groups, physicians of multiple fields are better equipped to identify a patient with DE for treatment. In general practice this knowledge paired with the longitudinal relationship built with an athlete puts the primary care physician at a unique intersection to allow for diagnosis and treatment of $\mathrm{DE}$, thus preventing progression to an ED, the female athlete 


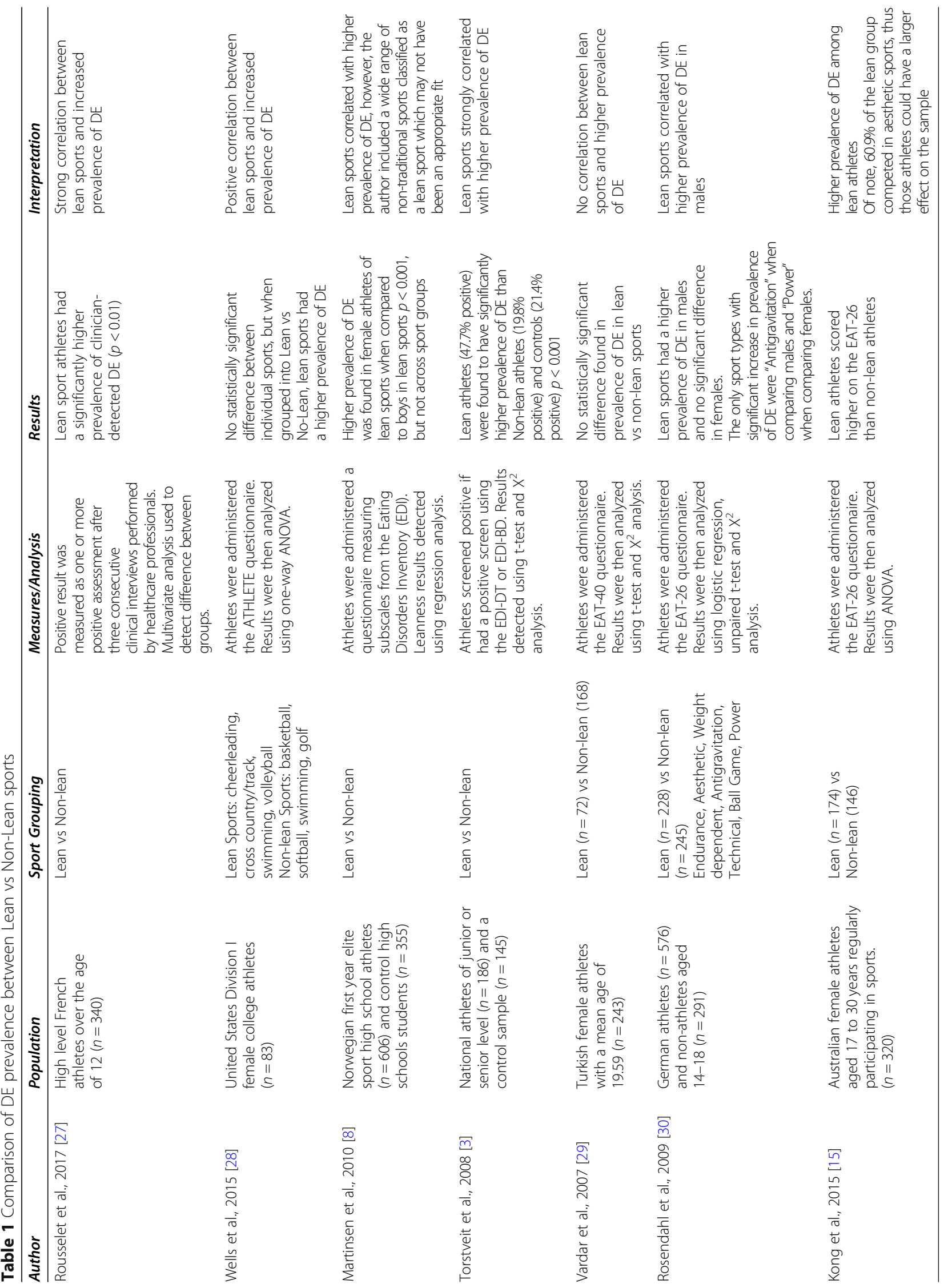




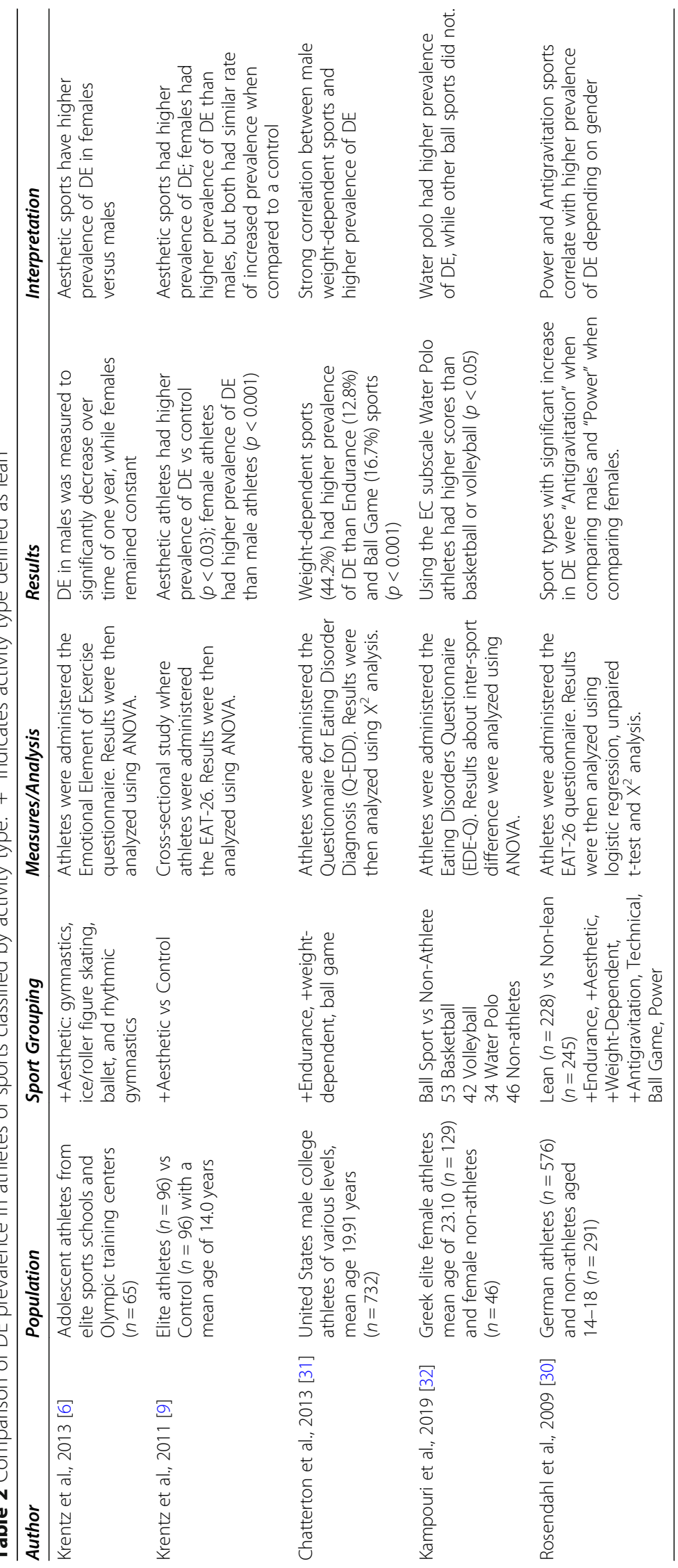


triad and RED-S, and other nutritional problems. Sports medicine physicians and ancillary staff having similar if not greater amounts of contact with athletes when compared to general practitioners should share a similar role, identification, and management. Psychiatrists, though they may have a lower level of exposure in order to screen for athletes, should be very aware of these higher risk groups. Given the relative ease of treatment for patients with DE in comparison to EDs, a psychiatrist or other healthcare professional with a properly prepared treatment plan can prevent the progression of $\mathrm{DE}$ to a more severe ED.

This systematic review is limited by the small availability of research on DE or EDs on specific athletes. Additionally, this research is limited by the fact that only one database was searched for article collection and the fact that no grey literature (literature produced by academic or commercial sources which was made available outside of traditional publishing processes) was considered. Future research regarding athletic groupings should be focused on uncovering pathological differences in the presentation of $\mathrm{DE}$ in these various sport categories. Subsequent research on DE and EDs should pay close attention to weight trends in various types of athletes. Despite these weaknesses, this research is the first of its kind to categorize the prevalence of DE in athletes. DE patterns in Aesthetic athletes and Weight-dependent athletes should specifically be addressed as rates in those two sport types show evidence of being particularly high. Future screening tools which are developed for the assessment of DE or EDs in athletes should be validated in wide ranges of athlete types as prevalence rates and symptom expression may be variable among different types of sports. Developing tools or performing research in a single athletic population will severely limit the generalizability of that research, and comprehensive, multi-sport research should be done when referring to athletes as a group.

\section{Conclusions}

Health professionals caring for athletes should be aware that there is strong evidence indicating athletes competing in lean sports are at higher risk for DE, especially Aesthetic athletes and male Weight-dependent athletes. However, as the risk in other sport types is not yet clear, all athletes should be screened for DE. All athletes should be provided education on proper nutrition and, if needed, resources for treatment of DE and EDs. It is critical to remember that not all athletes experience the same symptoms or symptom severity when performing research on DE or EDs in athletes or treating those pathologies as a physician. Although categorizations and groupings of athletes provide limited guidance when preparing an appropriate sample for data collection or treatment modality, a wide variety of athlete types provides a more representative example of an athletic population. Currently, there is not enough information to define specific sport populations based on risk for DE. If we are to properly address this problem, then further research needs to be completed with the aim of better identification of DE in athletes. As it currently stands, aesthetic athletes and the subgroups that compose it are the highest risk for disordered eating behavior.

\section{Abbreviations}

DE: Disordered eating; ED: Eating disorder; AN: Anorexia nervosa; BN: Bulimia nervosa; EAT-26: Eating Attitudes Test; OSFED: Other specified feeding and eating disorder; RED-S: Relative Energy Deficiency in Sport

\section{Acknowledgements}

Not applicable.

\section{Authors' contributions}

Ryley Mancine, Donald Gusfa, and Ali Moshrefi designed the study protocol. Ryley Mancine, Donald Gusfa, conducted literature searches and ruled in/out research studies according to the protocol. Donald Gusfa formulated the tables. Ryley Mancine, Donald Gusfa, and Ali Moshrefi wrote the first draft of the manuscript. Samantha Kennedy supervised all other authors and analyzed/revised the article critically. All authors contributed to and have approved the final manuscript.

\section{Authors' information}

RM and DG have been invited to speak regarded disordered eating and eating disorders in athletes from several organizations, including the Michigan Osteopathic Neuropsychiatric Society, for continuing medical education credit. RM and DG were awarded second place at the Michigan Osteopathic Association Scientific Research Exhibit competition, where they presented on the various types of athletes that exist in literature. RM was awarded first place at the research competition hosted by the Michigan Association of Osteopathic Family Practitioners for a similar topic. AM is a valuable member of our lab, who initially screened articles for the other authors to review and provided structure to the manuscript. SK is a child and adolescent psychiatrist who is primarily focused on the treatment of disordered eating and eating disorders, especially those effecting athletes. SK is currently developing a screening tool to accurately assess the risk of disordered eating in athletes of all levels of competition.

\section{Funding}

None.

Availability of data and materials

Not applicable - all citations provided.

Ethics approval and consent to participate Not applicable.

\section{Consent for publication}

Not applicable.

\section{Competing interests}

The authors declare that they have no competing financial interests.

\section{Author details}

${ }^{1}$ Medical Student, Michigan State University College of Osteopathic Medicine, Michigan State University, East Lansing, MI 48825, USA. ${ }^{2}$ Lab Personnel, Michigan State University College of Osteopathic Medicine, Michigan State University, East Lansing, Ml 48825, USA. ${ }^{3}$ Child and Adolescent Psychiatrist, Department of Psychiatry, Michigan State University, East Lansing, MI 48825, USA. 
Received: 31 January 2020 Accepted: 9 September 2020

Published online: 29 September 2020

\section{References}

1. Thompson RA, Sherman RT. Eating disorders in sport. New York: Routledge; 2010.

2. Wilson D, O'Connor EL. Mindfulness, personality and disordered eating. Personal Individ Differ. 2017;119:7-12.

3. Torstveit MK, Rosenvinge $\mathrm{JH}$, Sundgot-Borgen J. Prevalence of eating disorders and the predictive power of risk models in female elite athletes: a controlled study. Scand J Med Sci Sports. 2008;18(1):108-18.

4. Hudson J, Hiripi E, Pope H, Kessler R. The prevalence and correlates of eating disorders in the national comorbidity survey replication. Biol Psychiatry. 2007:61(3):348-58.

5. El Ghoch M, Soave F, Calugi S, Dalle GR. Eating disorders, Physical Fitness and Sport Performance: A Systematic Review. Nutrients. 2013;5:5140-60.

6. Krentz EM, Warschburger P. A longitudinal investigation of sports-related risk factors for disordered eating in aesthetic sports. Scand J Med Sci Sports. 2013;23(3):303-10.

7. Miyake Y, Okamoto Y, Jinnin R, Shishida K, Okamoto Y. Eating disorders. Brain Nerve. 2015;67(2):183-92.

8. Martinsen M, Bratland-Sanda S, Eriksson AK, Sundgot-Borgen J. Dieting to win or to be thin? A study of dieting and disordered eating among adolescent elite athletes and non-athletes controls. Br J Sports Med. 2010; 44(1):70-6.

9. Krentz EM, Warschburger P. Sports-related correlates of disordered eating in aesthetic sports. Psychol Sport Exerc. 2011;12(4):375-82.

10. Brown AJ, Parman KM, Rudat DA, Craighead LW. Disordered eating, perfectionism, and food rules. Eat Behav. 2012;13(4):347-53.

11. Yeager KK, Agostini R, Nattiv A, Drinkwater B. The female athlete triad: disordered eating, amenorrhea, osteoporosis. Med Sci Sports Exerc. 1993; 25(7):775-7.

12. Cobb KL, Bachrach LK, Greendale G, Marcus R, Neer RM, Nieves J, Sowers MF, Brown BW, Gopalakrishnan G, Luetters C, Tanner HK, Ward B, Kelsey JL. Disordered eating, menstrual irregularity, and bone mineral density in female runners. Med Sci Sports Exerc. 2003;35(5):711-9.

13. Mountjoy M, Sundgot-Borgen JK, Burke LM, Ackerman KE, Blauwet $C$, Constantini $\mathrm{N}$, et al. IOC consensus statement on relative energy deficiency in sport (RED-S): 2018 update. Br J Sports Med. 2018;52(11):687-97.

14. Reinking MF, Alexander LE. Prevalence of disordered-eating behaviors in undergraduate female collegiate athletes and nonathletes. J Athl Train. 2005:40(1):47-51.

15. Kong $P$, Harris LM. The sporting body: body image and eating disorder symptomatology among female athletes from leanness focused and nonleanness focused sports. Aust J Psychol. 2015;149(1-2):141-60.

16. Werner A, Thiel A, Schneider S, Mayer J, Giel KE, Zipfel S. Weight-control behaviour and weight-concerns in young elite athletes- as systematic review. J Eat Disord. 2013;1:18.

17. Orbitello B, Ciano R, Corsaro M, Rocco PL, Taboga C, Tonutti L, Armellini M, Balestrieri M. The EAT-26 as screening instrument for clinical nutrition unit attenders. Int J Obes. 2006:30(6):977-81.

18. Murphy SM. The sport psych handbook. Champaign: Human Kinetics; 2005.

19. McFee G. Officiating in aesthetic sports. J Philos Sport. 2013:40(1):1-17.

20. Kantanista A, Glapa A, Banio A, Firek W, Ingarden A, Malchrowicz-Mośko E, Markiewicz P, Ploszaj K, Ingarden M, Maćkowiak Z. Body image of highly trained female athletes engaged in different types of sport. Biomed Res Int. 2018;2018(Article ID 6835751):8.

21. Sundgot-Borgen J, Torstveit MK. Prevalence of eating disorders in elite athletes is higher than in the general population. Clin J Sport Med. 2004; 14(1):25-32

22. Morici G, Gruttad'Auria Cl, Baiamonte P, Mazzuca E, Castrogiovanni A, Bonsignore MR. Endurance training: is it bad for you? Breathe (Sheff). 2016; 12(2):140-7.

23. Weber SE, Harris MM, Wright HH, Manore MM. Assessment of disordered eating and orthorexia nervosa in endurance athletes following gluten and wheat-free diets (GWD). Med Sci Sports Exerc. 2017:49:712.

24. Sigmon CH, Pudwill N, Rothman MS, Saint-Phard D, Santo K, Yin X. Poster 191 is there evidence of disordered eating in high-endurance male collegiate athletes. Am J Phys Med Rehabil. 2011;3(10S1):S236.
25. Slater G, Phillips SM. Nutrition guidelines for strength sports: sprinting weightlifting, throwing events, and bodybuilding. J Sports Sci. 2011;29(S1): S67-77.

26. Navalta JW, Stone WJ, Lyons S. Ethical Issues Relating to Scientific Discovery in Exercise Science. Int J Exerc Sci. 2019;12(1).

27. Rousselet M, Guérineau B, Paruit MC, Guinot M, Lise S, Destrube B, RuffioThery S, Dominguez N, Brisseau-Gimenez S, Dubois V, Mora C, Trolonge S, Lambert S, Grall-Bronnec M, Prétagut S. Disordered eating in French highlevel athletes: association with type of sport, doping behavior, and psychological features. Eat Weight Disord. 2017;22(1):61-8.

28. Wells EK, Chin AD, Tacke JA, Bunn JA. Risk of disordered eating among division I female college athletes. Int J Exerc Sci. 2015;8(3):256-64.

29. Vardar E, Vardar SA, Kurt C. Anxiety of young female athletes with disordered eating behaviors. Eat Behav. 2007;8(2):143-7.

30. Rosendahl J, Bormann B, Aschenbrenner K, Aschenbrenner F, Strauss B. Dieting and disordered eating in German high school athletes and nonathletes. Scand J Med Sci Sports. 2009;19(5):731-9.

31. Chatterton JM, Petrie TA. Prevalence of disordered eating and pathogenic weight control behaviors among male collegiate athletes. Eat Disord. 2013; 21(4):328-41.

32. Kampouri D, Kotopoulea-Nikolaidi M, Daskou S, Giannopoulou I. Prevalence of disordered eating in elite female athletes in team sports in Greece. Eur J Sport Sci. 2019;19(9):1267-75

\section{Publisher's Note}

Springer Nature remains neutral with regard to jurisdictional claims in published maps and institutional affiliations.
Ready to submit your research? Choose BMC and benefit from:

- fast, convenient online submission

- thorough peer review by experienced researchers in your field

- rapid publication on acceptance

- support for research data, including large and complex data types

- gold Open Access which fosters wider collaboration and increased citations

- maximum visibility for your research: over $100 \mathrm{M}$ website views per year

At $\mathrm{BMC}$, research is always in progress.

Learn more biomedcentral.com/submissions 